Report No. BMI-1296

UC-25 Metallurgy and Ceramics

(TID-4500, 13th Ed., Rev.)

Contract No. W $-7405-$ eng -92

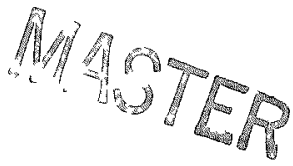

NIOBIUM CARBIDE COATING OF GRAPHITE TUBES

by

John M. Blocher, Jr.

Melvin F. Browning

Don P. Leiter, Jr.

Ivor E. Campbell

October 6, 1958

BATTELLE MEMORIAL INSTTTUTE

505 King Avenue

Columbus 1, Ohio 


\section{DISCLAIMER}

This report was prepared as an account of work sponsored by an agency of the United States Government. Neither the United States Government nor any agency Thereof, nor any of their employees, makes any warranty, express or implied, or assumes any legal liability or responsibility for the accuracy, completeness, or usefulness of any information, apparatus, product, or process disclosed, or represents that its use would not infringe privately owned rights. Reference herein to any specific commercial product, process, or service by trade name, trademark, manufacturer, or otherwise does not necessarily constitute or imply its endorsement, recommendation, or favoring by the United States Government or any agency thereof. The views and opinions of authors expressed herein do not necessarily state or reflect those of the United States Government or any agency thereof. 


\section{DISCLAIMER}

Portions of this document may be illegible in electronic image products. Images are produced from the best available original document. 


\title{
NIOBIUM CARBIDE COATING OF GRAPHITE TUBES
}

\author{
John M. Blocher, Jr, Melvin F. Browning, Don P. Leiter, Jr., \\ and Ivor E. Campbell
}

\begin{abstract}
Graphite tubes having a length-to-bore-diameter ratio of 430 were coated on the inside with uniform adherent layers of niobium carbide in thiclnesses of 0.002 and $0.004 \mathrm{in}$.
\end{abstract}

Intimate conformity to the graphite surface and improved uniformity were obtained by reacting $\mathrm{NbCl} 5$ vapor with the graphite under pressure-temperature conditions thermodynamically unfavorable for the deposition of niobium by thermal dissociation of the chloride, but favorable for the fornation of $N b C$. Thus, the rate of coating formation depended primarily on the rate of diffusion of carbon through the carbide, which is a function of tempenture and independent of vaporflow considentions over a uide range.

Although adherent coatings were obtained on a porous uranium-loaded graphite in the as-received condition, it was necessary to etch a more dense graphite to promote adherence.

\section{INTR.ODUCTION}

The research outlined in this report is an extension of earlier work $(1,2)$ in which an improved process was developed for the protective carbide coating of graphite by vapor deposition. In view of promising results obtained in the prior work, the development of the process to coat specimens of a new design was undertaken. The specimen geometry, which was chosen to obtain more definitive data on the protective characteristics of the coatings, was much less favorable relative to the prospect of obtaining uniform coatings.

\section{Description of Coating Process}

Despite the various advantages of coatings prepared by conventional vapordeposition processes (3), the rate of deposition is generally controlled by kinetic or mass-transfer considerations at the vapor-solid interface, and nonuniform coatings are generally obtained. Some improvement can be made in the uniformity by controlled vapor flow and localized heating. However, these approaches are of limited value, particularly in instances of complicated geometry. It was to overcome this deficiency that the present vapor-deposition process was developed.

In principle, the process consists of treating the base material with a metalhalide vapor (or other suitable volatile compound) under pressure-temperature conditions thermodynamically favorable to compound formation between the metal and the base, but unfavorable to the deposition of free metal by the thermal dissociation of the halide. In this way, the rate of coating formation can be made dependent on the rate of

(1) References at end. 
solid-solid diffusion of material from the base and independent of vapor-flow conditions over a wide range. To obtain uniform coating, it is only necessary that the temperature of the body be uniform and that the rate of mass transfer at the vapor-solid interface exceed the solid-solid diffusion rate at all points.

The theoretical justification and experimental demonstration of the existence of the appropriate pressure-temperature conditions were reported $(1,2)$ in the earlier work on the formation of $\mathrm{NbC}, \mathrm{TaC}$, and $\mathrm{ZrC}$ coatings on graphite by reaction with $\mathrm{NbBr}_{5}, \mathrm{NbCl}_{5}, \mathrm{TaBr}_{5}, \mathrm{TaCl} 1_{5}, \mathrm{ZrBr}_{4}, \mathrm{ZrCl}_{4}$, and $\mathrm{ZrI}_{4}$.

\section{Definition of Coating Problem}

In the present work, coatings were applied to the bores of two types of tubes: (1) those machined from commercial graphite (National Carbon Company, Type CCU), and (2) those extruded with a loading of $0.125 \mathrm{~g} \mathrm{per} \mathrm{cm}^{3}$ of uranium. The tubes were $0.375 \mathrm{in}$. in $O D, 0.065$ to $0.07 \mathrm{in}$. in ID, and $30 \mathrm{in.}$ long. The ends were threaded and provided with a convex conical seat.

The length-to-diameter ratio of the specimens (430) was much greater than that (72) encountered in the prior coating of 18-in. -long by 1/4-in. -diameter bores. This condition requires a greater linear vapor velocity to support the same coating rate and to avoid equilibration of the vapor and consequent thinning of the coating toward the vapor-exit end of the tube. However, increased vapor velocity can be obtained only by increasing the pressure drop from one end of the bore to the other. In the extreme, this could prevent deposition at the vapor-entrance end of the tube if the pressure there were to exceed the limiting pressure for carbide formation. * Preliminary calculations indicated that the pressure drop through the tube would be of the order of that required to give this effect. However, in view of the uncertainties in estimating viscosity and degree of dissociation, the behavior of the longer tube in this regard could not be predicted with certainty.

Another problem associated with the new geometry was the poor rigidity of the specimens. This required development of alternative electrodes. Whereas compressive electrodes were used to conduct heating current to the $3 / 4$-in. -OD by 18 -in. -long specimens coated in the earlier work, the present specimens bowed prohibitively under the compressive force necessary for good electrical contact.

A third problem requiring solution in the present work resulted from the high density of the unloaded Type CCU graphite specimens. Coatings applied to these tubes were invariably cracked in several places and were nonadherent. In fact, several 3 to 6 -in. lengths of uniform 0.07 -in. $-O D$ by $0.06-$ in. - ID niobium carbide tubing could be recovered from the bores of the specimens. This behavior was not surprising, since it had been already pointed out in the earlier work (4) that the adherence characteristic of those coatings could be attributed to the great throwing power of the coating process which "rooted" the coating to the porous structure of the graphite. Thus, it was necessary in the present work to etch the dense graphite specimens before coating, to provide a surface to which the coatings would adhere.

When these three development problems had been solved, a large number of specimens were coated routinely.

*The limiting pressure is that above which "chewing" reactions such as $2 \mathrm{NbC}(\mathrm{s})+3 \mathrm{NbCl} 5(\mathrm{~g})$ o $5 \mathrm{NbCl} 3(\mathrm{~g})+2 \mathrm{C}(\mathrm{s})$ occur [see References (1) and (2)]. 
Coating Conditions

It had been determined in the earlier research that in the reaction of $\mathrm{NbCl}_{5}$ vapor with graphite, good results were obtained at $2100 \mathrm{C}$ with a pressure of $50 \mathrm{~mm}$ of mercury. Although a significant pressure drop was expected through the smaller bore of the present specimens, it was hoped that the effective pressure-temperature condition would fall within the area for niobium -f $\mathrm{r}$ ee $\mathrm{NbC}$ formation determined earlier

(Figure 1). Fortunately, this proved to be the case.

In several exploratoxy experiments, it was determined that, below $2100 \mathrm{C}$, the rate of coating was lower than desirable; above $2100 \mathrm{C}$, the loaded specimens deteriorated badly, becoming more fragile and, in some cases, showing cleavage between coaxial layers of graphite. Therefore, most of the specimens were coated at $2100 \mathrm{C}$ and $50 \mathrm{~mm}$ of mercury.

\section{EQUIPMENT AND PROCEDURES}

\section{Coating Apparatus}

The apparatus used to coat the present specimens was similar in principle to that used earlier. The specimen coater in its final form is shown schematically in Figure 2. The resistively heated specimen, surrounded by a graphite radiation-shielding capsule, is held in tension between two graphite adaptors extending well into the capsule to reduce thermal end losses. Since in the present work it was necessary only to coat the bore of the specimens, no provision had to be made for vapor flow around the specimen. Thus it was possible to provide a hole through the radiation shield for direct observation of the specimen temperature.

As in the prior work, the $\mathrm{NbCl}_{5}$ fed to the specimen was vaporized in a resistively heated tube connected to the lower specimen adaptor. Electrical connections to this vaporizer were made through the bottom of the vacuum tank and to the electrode plate common to the specimen.

Improved control of vaporization was obtained by operating the vaporizer above the melting point of $\mathrm{NbCl}_{5}(209.5 \mathrm{C})$. This resulted in better and more predictable heat transfer. Since the $235 \mathrm{-mm}$ vapor pressure $\mathrm{e}^{(5)}$ of $\mathrm{NbCl}_{5}$ at its melting point exceeds the $50-\mathrm{mm}$ pressure chosen for the coating atmosphere, it was necessary to use a gastight vaporizer and provide it with a constriction to maintain the pressure differential. Thus, the vaporizer was constructed of stainless steel tubing $1 / 16 \mathrm{in}$. in wall thickness and capped with a 1/4-in. plug of ATJ graphite which was suitably porous for the application.

Heating current to the electrode plates at either end of the specimen-adaptor assembly was carried through water-cooled copper tubing coiled for flexibility. Both electrode plates were free to move with expansion of the vaporizer and specimen. The upper plate was suspended from coiled springs of appropriate strength to maintain the specimen in tension and at the same time permit an adequate fraction of the weight of the assembly to bear on the electrical contact at the bottom of the vaporizer. 


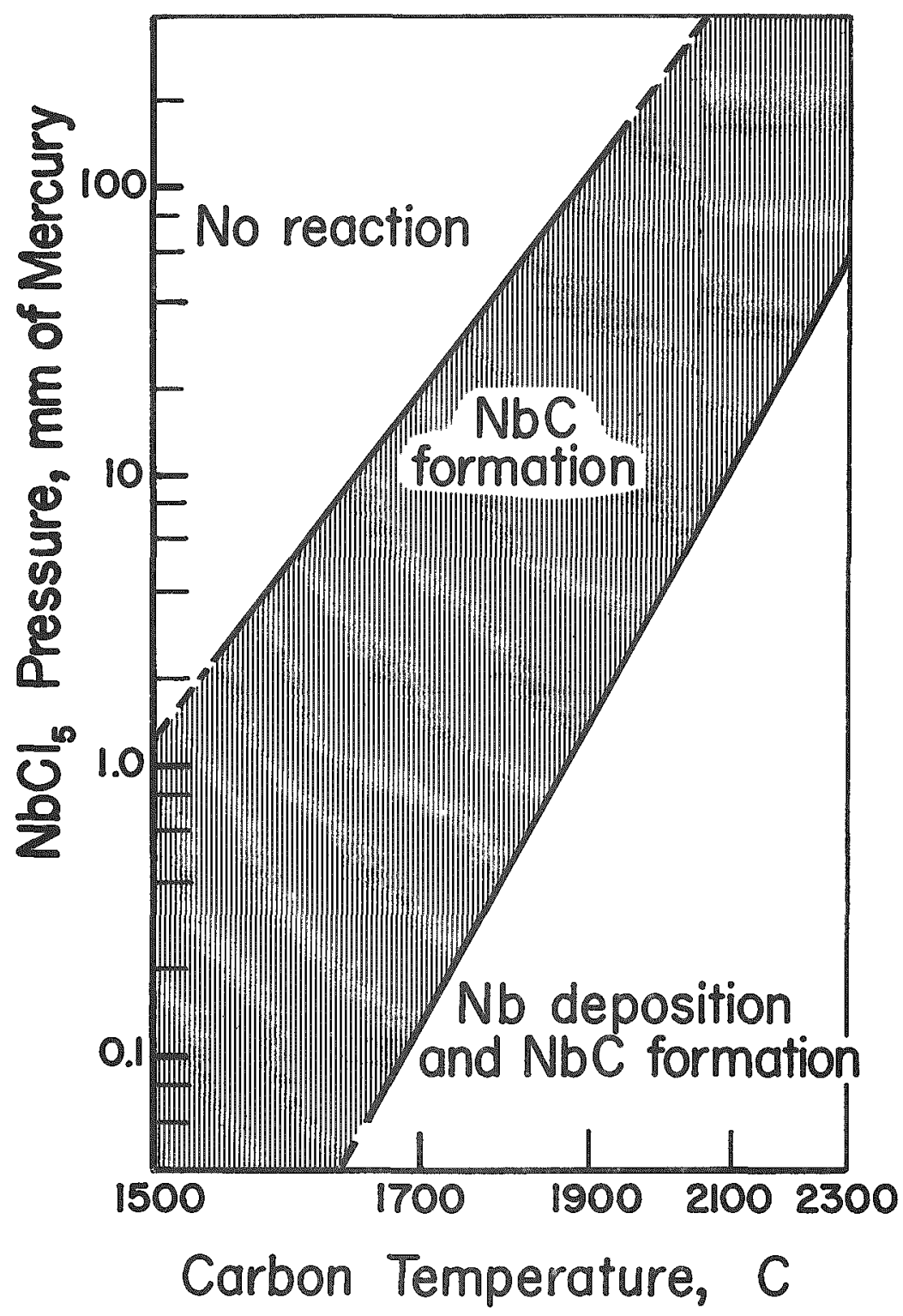

FIGURE 1. PRESSURE-TEMPERATURE REGION FOR NIOBIUM-FREE NbC FORMATION IN THE REACTION OF $\mathrm{NbCl}_{5}$ VAPOR WITH CARBON Data from References 1 and 2 . 


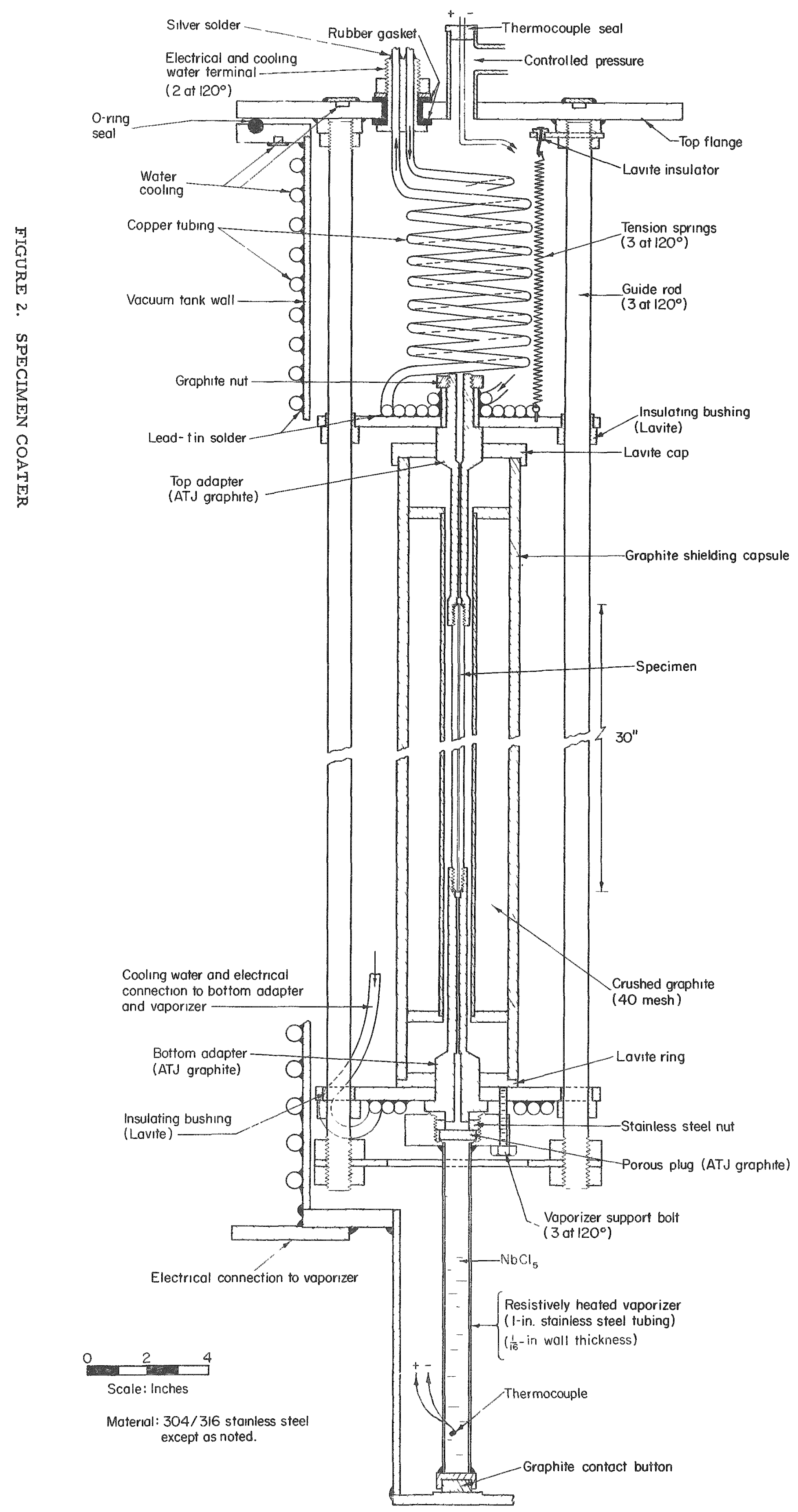


O. . . 
Power to the specimen was supplied by a thyratron-controlled welding trans former. Vaporizer power was supplied through a step-down transformer connected to a variable autotransformer.

The ambient pressure was controlled by intermittent pumping against the normal outgassing of the unit. The valve to the vacuum line was actuated by the signal from a preset adjustable mercury manometer. The vacuum system consisted of a liquidnitrogen-cooled trap and a Cenco Hypervac-25 pump.

Niobium Pentachloride Preparation

The niobium pentachloride used in the present work was prepared by synthesis from the elements in the apparatus shown in Figure 3. Technical Grade TA-P-262G niobium powder, having the analysis given in Table 1 , was obtained from Hermann $C$. Starck Aktiengesellschaft through the Shieldalloy Corporation of Newficld, New Jersey.

TABLE 1. ANALYSIS OF NIOBIUM POW DER

\begin{tabular}{llll}
\hline \multicolumn{4}{c}{ Analysis (Balance Nominally Niobium) } \\
\hline Element & w/o & Element & w/o \\
\hline Iron & 0.04 & Copper & 0.00 \\
Chromium & 0.00 & Titanium & 0.05 \\
Nickel & 0.09 & Zirconium & 0.00 \\
Tantalum & 2.0 & Cobalt & 0.00 \\
Silicon & 0.04 & Nitrogen & 0.10 \\
Manganese & 0.00 & Hydrogen & 0.002 \\
Hafnium & 0.00 & Oxygen & 0.91 \\
Aluminum & 0.01 & Carbon & 0.09 \\
Molybdenum & 0.00 & & \\
\hline \hline
\end{tabular}

Since the deposition conditions for $\mathrm{NbC}$ and $\mathrm{TaC}$ from their respective chlorides are comparable $(1,2)$, and since the two form a continuous series of solid solutions $(6)$, it was predicted that the tantalum/niobium atom ratio in the coating would be little, if any, greater than the 0.010 in the feed, and that this would not significantly affect the properties of the coating. Spectrographic analysis of a sample of coating prepared at $2100 \mathrm{C}$ and $50 \mathrm{~mm}$ of mercury confirmed the expected tantalum/niobium atom ratio of 0.010 .

In order to decrease the effective surface area of the niobium and make it easier to handle, the powder was compacted into 1-in. -diameter "pills" which were then broken into 1/2-in. Iumps and charged to the chlorinator. After a purge with dry, gettered argon, the chlorinator temperature was raised to between 600 and $650 \mathrm{C}$. Chlorine (Matheson Company, Inc.) was then introduced at a convenient rate sufficient to maintain an excess and a steady "snow" (about $100 \mathrm{~g}$ per hr) of $\mathrm{NbCl}_{5}$ in the condenser. A slow flow of argon was maintained through the chlorinator to avoid a. "vacuum" should the chlorine flow fall off accidentally. The bright yellow NbCl5 prepared in this manner was transferred in a dry box as needed from the 1-liter receiver to the vaporizer of the coating apparatus. Care was taken to minimize the time of contact with air on removing and stoppering the 1-liter receiver from the chlorinator and 


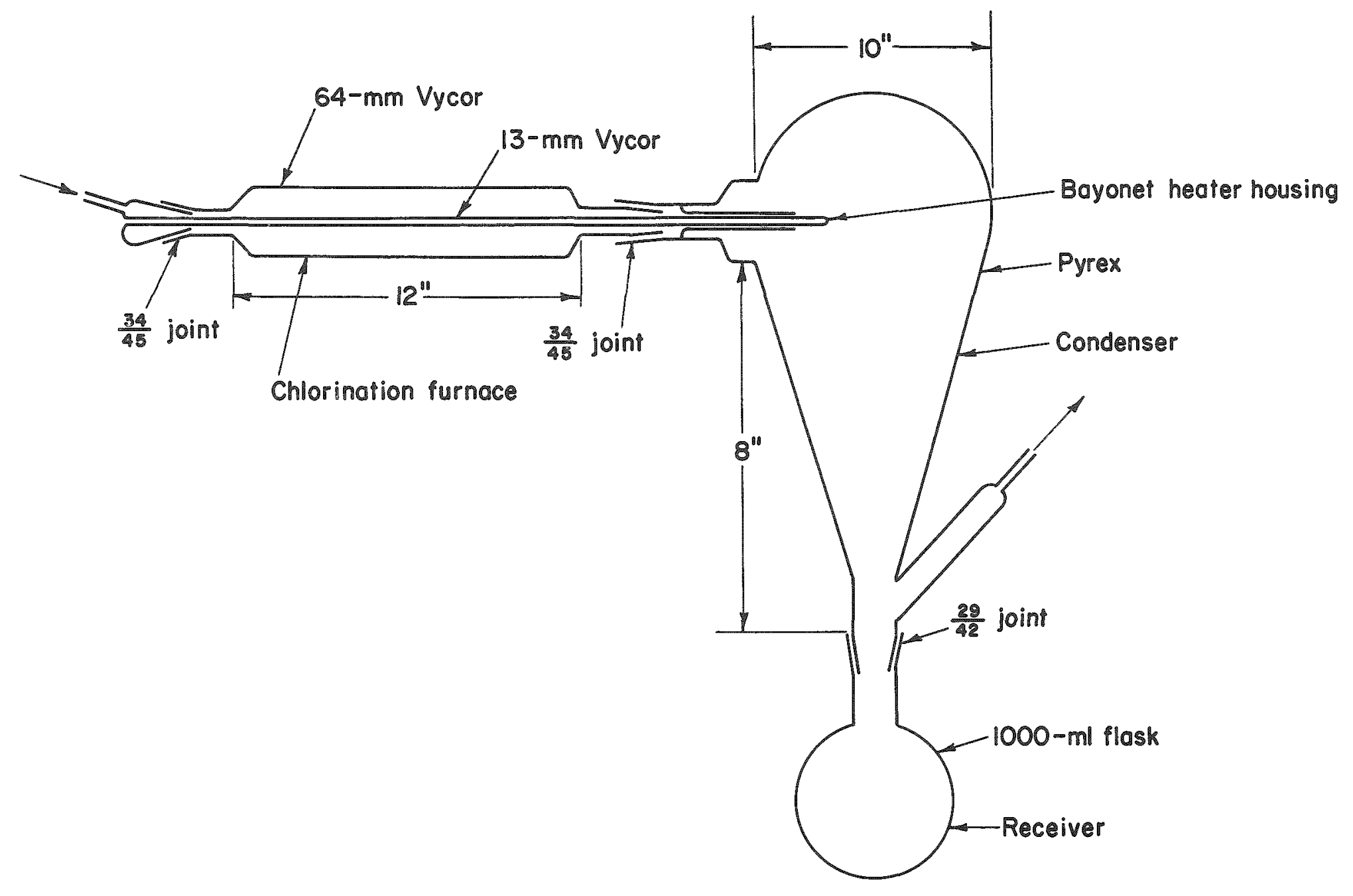

$\infty$

FIGURE 3. CHLORINATOR 
connecting an argon-filled substitute. In this way, formation of the white hydrolysis product $\mathrm{NbOCl}_{3}$ was minimized. Once charged with $\mathrm{NbCl}_{5}$, the vaporizer could be handled more leisurely since the porous plug restricted the diffusion of air to the chloride.

\section{Coating Procedure}

Briefly, the coating procedure consisted of assembling the unit, evacuating to $50 \mu$ and backfilling to $50 \mathrm{~mm}$ of mercury, heating the specimen to $2100 \mathrm{C}$, and energizing the vaporizer on a power schedule shown by experience to give a fairly steady rate of vaporization over the desired coating period. Bursts of $\mathrm{NbCl}_{5}$ smoke, entrained in the exhaust as the pump cut in and out, gave a useful indication of the rate of vaporization.

When coating had been completed, the unit was permitted to cool in an atmosphere of helium for $3 / 4 \mathrm{hr}$. It was then opened and the specimen, graphite parts, and vaporizer were removed from the head assembly. The head assembly and tank were washed free of $\mathrm{NbCl}_{5}$ with a water spray, rinsed with acetone, and dried with heat lamps. The vaporizer was independently cleaned and dried. Since the graphite shielding capsule operated above the dew point of the plating atmosphere, it required no cleaning at the end of a run other than to wipe "feathers" of accumulated hydrolysis product from the sight-port hole. The specimen adaptors were used for about six runs before replacement. The porous vaporizer plug was replaced after about 12 runs.

At $2100 \mathrm{C}$, coating for 20 to $30 \mathrm{~min}$ gave 1 to 2 mils of NbC. A 1 -hr period was used to obtain 3 to 4-mil coatings. Table 2 gives data for a typical run.

Etching Procedure for Dense-Graphite Specimens

As mentioned earlier, it was suspected that the dense surface of the Type CCU graphite specimens was not susceptible to permeation and anchoring of the coating, thus accounting for the lack of adherence. Air oxidation of the resistively heated specimens was explored as a means of suitably etching the surface. The approach was somewhat empirical in that the specimen temperature during oxidation was not accurately determined. Five thermocouples in contact with the outside surface of the specimen gave variable minimal readings. Therefore an uncalibrated Ray-O-Tube* was used to give an empirical indication of the temperature level.

Thus it was determined that air oxidation with dry air for $1 \mathrm{hr}$ at a flow of 0.3 $\mathrm{cfm}$ through the bore at an unknown but reproducible temperature between 700 and $800 \mathrm{C}$ roughened the surface sufficiently to promote adherence without enlarging the bore by more than $0.005 \mathrm{in.}$ To improve the uniformity of etching, the direction of air flow was reversed at the end of $1 / 2 \mathrm{hr}$.

Although the above treatment was sufficient to eliminate cracks observable by radiographic examination under a magnification of $20 \mathrm{X}$, it would be quite desirable at some time to optimize the treatment by correlation with a quantitative adherence test.

"Leeds and Northrup bolometer. 
TABLE 2. TYPICAL COATING DATA

$\begin{array}{ll}\text { Run } & 15027-90-173 \\ \text { Specimen } & \mathrm{C}-98 \\ \text { Furnace } & 1 \\ \text { Pressure } & 50 \mathrm{~mm} \text { of mercury } \\ \mathrm{NbC1}_{5} & \\ \quad \text { Charged } & 88 \mathrm{~g} \\ \text { Vaporizer residue } & 30 \mathrm{~g} \\ \text { Used } & 58 \mathrm{~g}\end{array}$

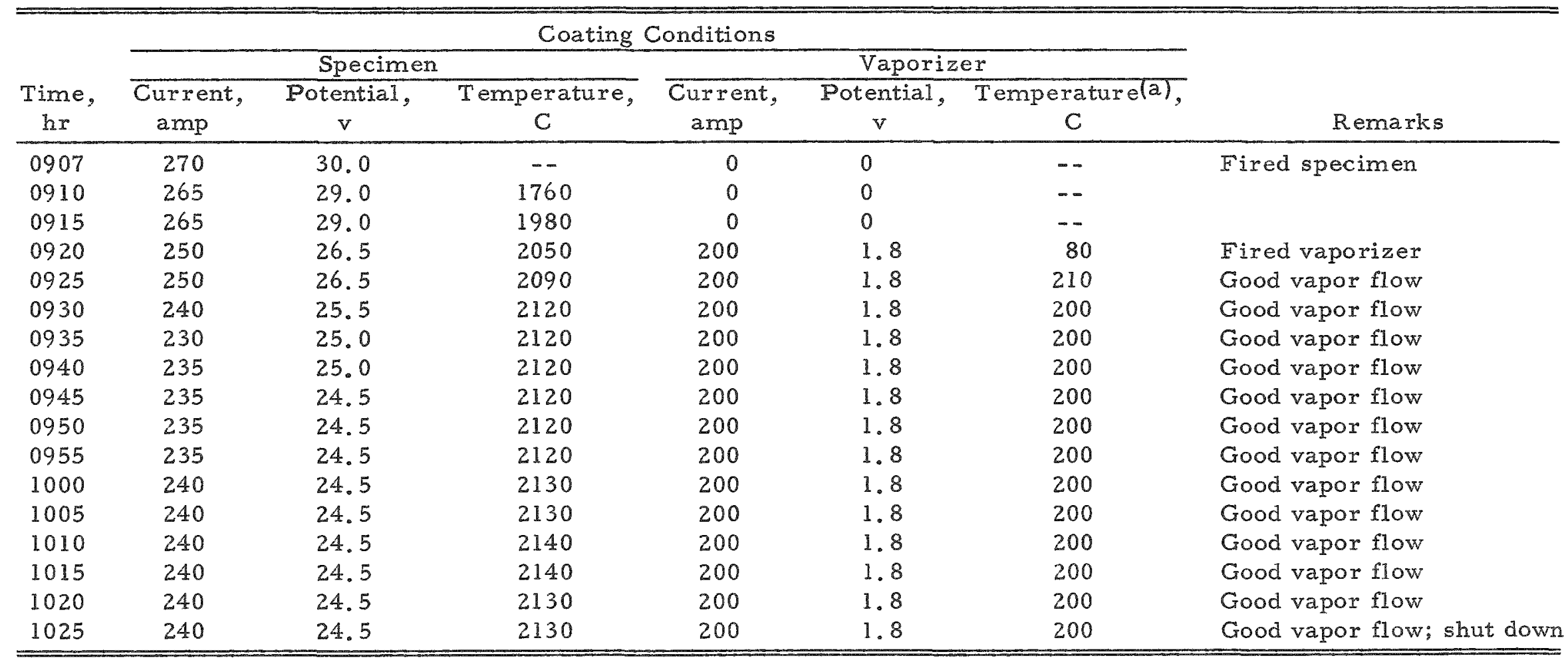

(a) This reference temperature, indicated by the themocouple 2 in. from the couled botton end of the vaporizer, is lower than the average vaporization temperature. Fusion of the $\mathrm{NbCl}_{5}$ during the run indicated a vaporization temperature in excess of the melting point, $209.5 \mathrm{C}$. 
PROPERTIES OF THE NIOBIUM CARBIDE COATINGS

The principal means of evaluating the coatings was by radiography, the graphite base being practically transparent relative to the $\mathrm{NbC}$ coating. Microscopic examination and densitometric measurement of the radiographs were used to establish the integrity and thickness of the coatings. In addition, several representative samples were sectioned for metallographic examination.

Samples of the coatings from loaded and unloaded tubes were examined by $\mathrm{X}-\mathrm{ray}$ diffraction to test the prediction that there should be no significant substitution of uranium for niobium in the NbC lattice, since, as noted in the earlier work, the uranium is leached from the surface by the vapor.

\section{X-Ray Diffraction Examination}

As in the prior work, X-ray diffraction examination of the NbC coatings prepared by reaction of $\mathrm{NbCl}_{5}$ with the pure graphite base at $2100 \mathrm{C}$ and $50 \mathrm{~mm}$ of mercury showed them to be of the cubic ( $\mathrm{NaCl}$ type) structure having a lattice constant $\mathrm{a}_{\mathrm{o}}=$ $4.469 \pm 0.002 \mathrm{~A}$. This is somewhat higher than the $4.461 \mathrm{~A}$ chosen by Schwarzkopf and Kieffer $(6)$ from the literature as the most reliable. However, a later determination by Brauer, et al.(7) gave $a_{0}=4.4661 \mathrm{~A}$, which is very close to the present value.

The lattice constant of a sample of coating from a loaded tube was $a_{0}=4.469 \pm$ $0.001 \mathrm{~A}$. Since the lattice constant of the UC-NbC solid-solution system obeys Vegard's law between the limits $4.46 \mathrm{~A}$ at $\mathrm{NbC}$ and $4.96 \mathrm{~A}$ at $\mathrm{UC}(8)$, the lack of distortion (within $\pm 0.002 \mathrm{~A}$ ) indicates the presence of less than 0.004 atom of uranium per atom of niobium in the lattice.

\section{Metallographic Examination}

Figure 4 shows a coating of $\mathrm{NbC}$ on ATJ graphite obtained in the earlier work. The characteristic surface conformity and penetration of the porous structure of the graphite are evident. The loaded tubes coated in the present work appeared to be of equal or greater porosity. Hence the similar anchoring of the coating shown in Figure 5.

By contrast, coatings on the dense graphite (Type CCU) showed no penetration of the surface, resulting in poor adherence as the shear strength exceeded the adhesive strength and large segments of the coating cracked away due to differential contraction on cooling. This type of structure is illustrated in the photomicrograph of Figure 6. 


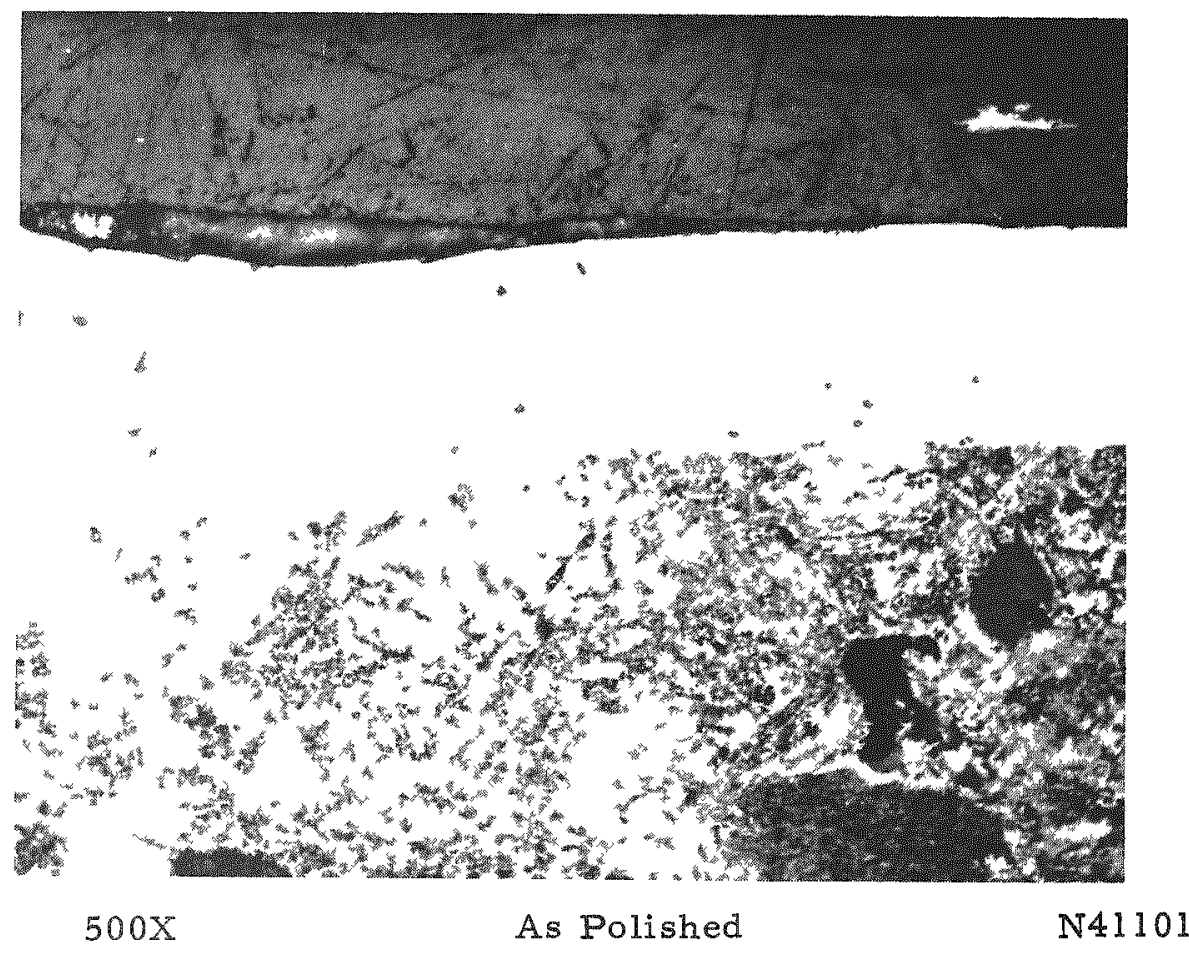

FIGURE 4 NIOBIUM CARBIDE COATING ON ATJ GRAPHITE

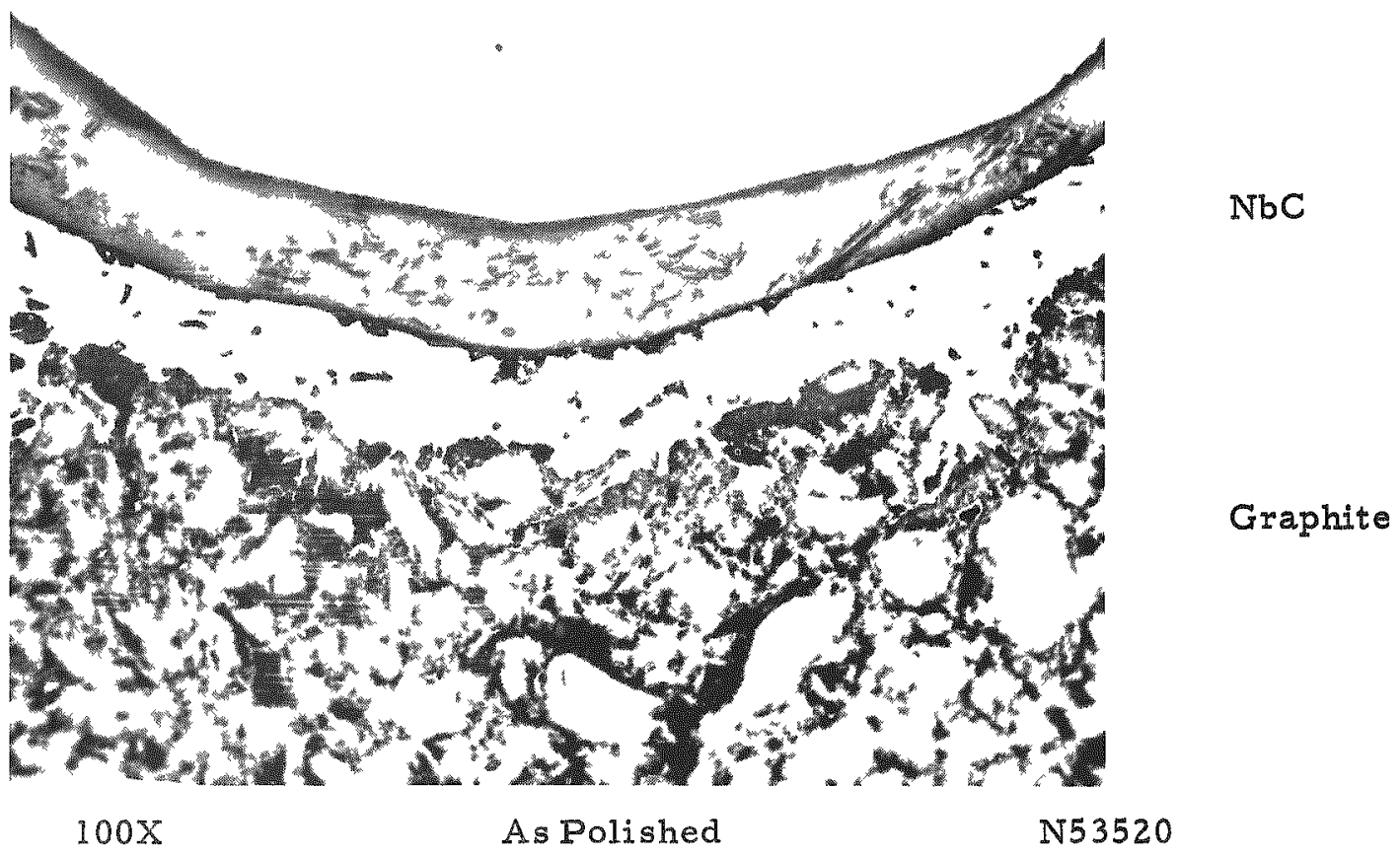

FIGURE 5. NIOBIUM CARBIDE ON URANIUM-LOADED GRAPHITE 


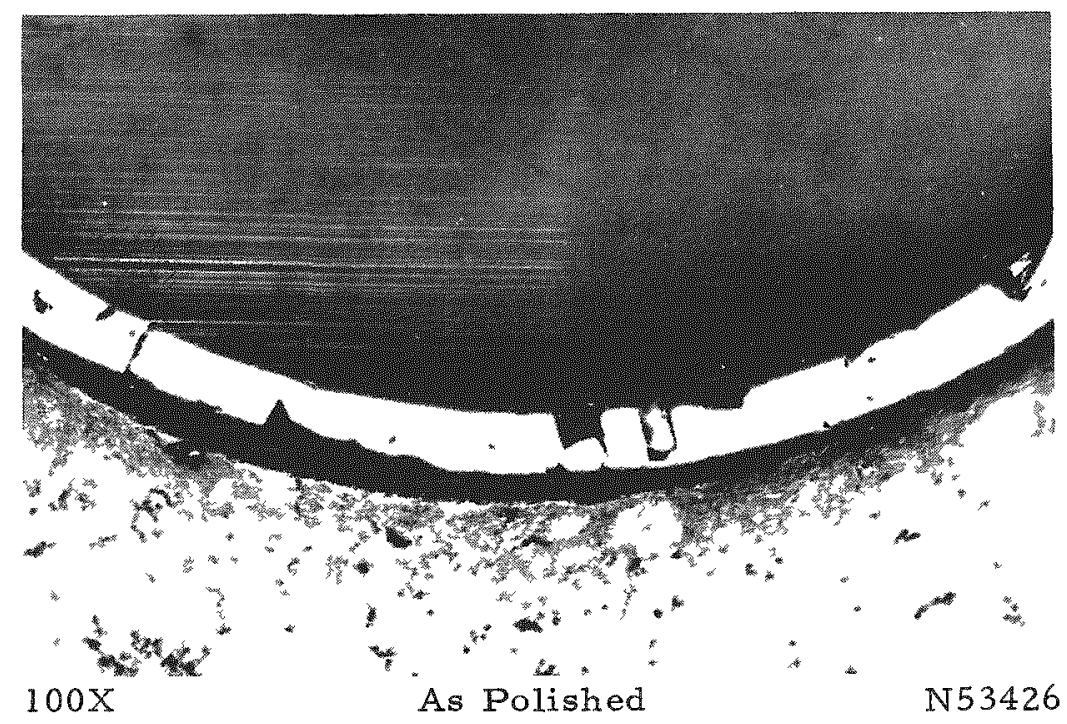

\section{FIGURE 6. NIOBIUM CAR BIDE COATING ON TYPE CCU GRAPHITE}

The etching treatment described on page 9 of this report results in the pittedsurface structure to which the coating conforms as shown in Figure 7. This anchoring effect prevents gross cracking of coatings applied to the dense graphite. It will be noted, however, that there are a multitude of stress-relieving intergranular separations in Figure 7 which are not evident in the coating of the loaded tube (Figure 5). This is attributed to the difference in the shear strengths of the two types of graphite. In the more porous variety, the graphite structure rather than the coating yields on differential contraction as indicated by small cracks in the graphite. Despite the intergranular separations evident in the coating shown in Figure 7 , it is believed that such coatings would offer significant corrosion protection in many applications, since the attack of the graphite would be limited by diffusion rather than by convection.

Figure 8, showing a portion of the coating of a tube sectioned at a slight angle to its axis, reveals several significant features. In the first place, it shows the absence of surface penetration of the dense graphite base. Secondly, it illustrates the essentially smooth outer surface of the coating, a characteristic which, in the thicker coatings, appears to be independent of the nature of the base material once the pores are filled. The third feature of interest is the raised surface along the grain boundaries. This is difficult to discern in Figure 8, but is quite evident in focusing a microscope on the grain boundaries and adjacent areas. Such a raised surface indicates a more rapid diffusion of carbon along the grain boundary than through the grains during formation of the coating.

It is thought that the cracks evident in Figure 8 were produced in cutting and polishing the specimen, since no longitudinal cracks of this nature have been observed in radiographs of the specimens.

Radiographic Examination

As indicated above, radiographic examination was the principal method of assessing the integrity and uniformity of the coatings. A $40 \mathrm{ma}-\mathrm{min}$ exposure to 65 $\mathrm{kv} X$-rays from a tungsten target with the specimens on Type $M$ film 68 in. from the 


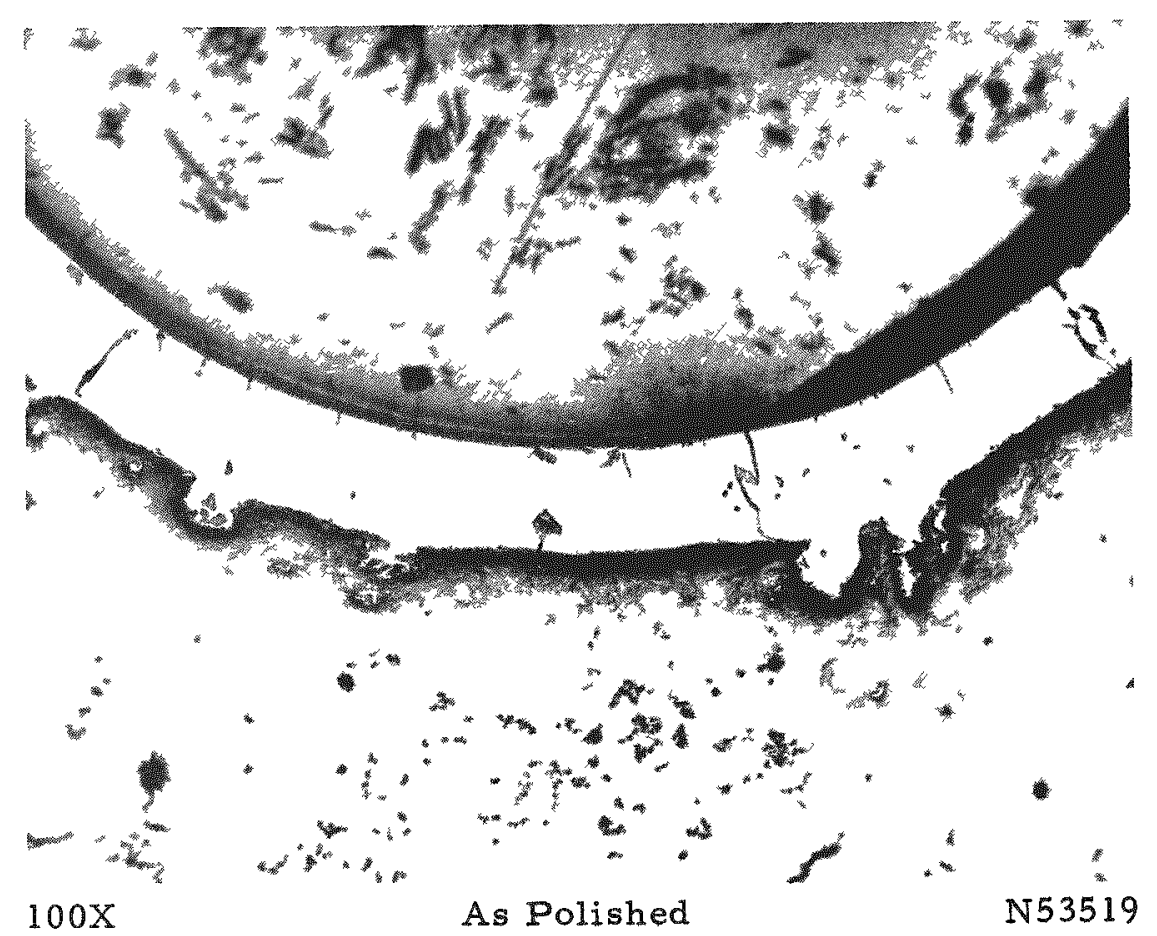

FIGURE 7. NIOBIUM CARBIDE COATING ON ETCHED-TYPE CCU GRAPHITE

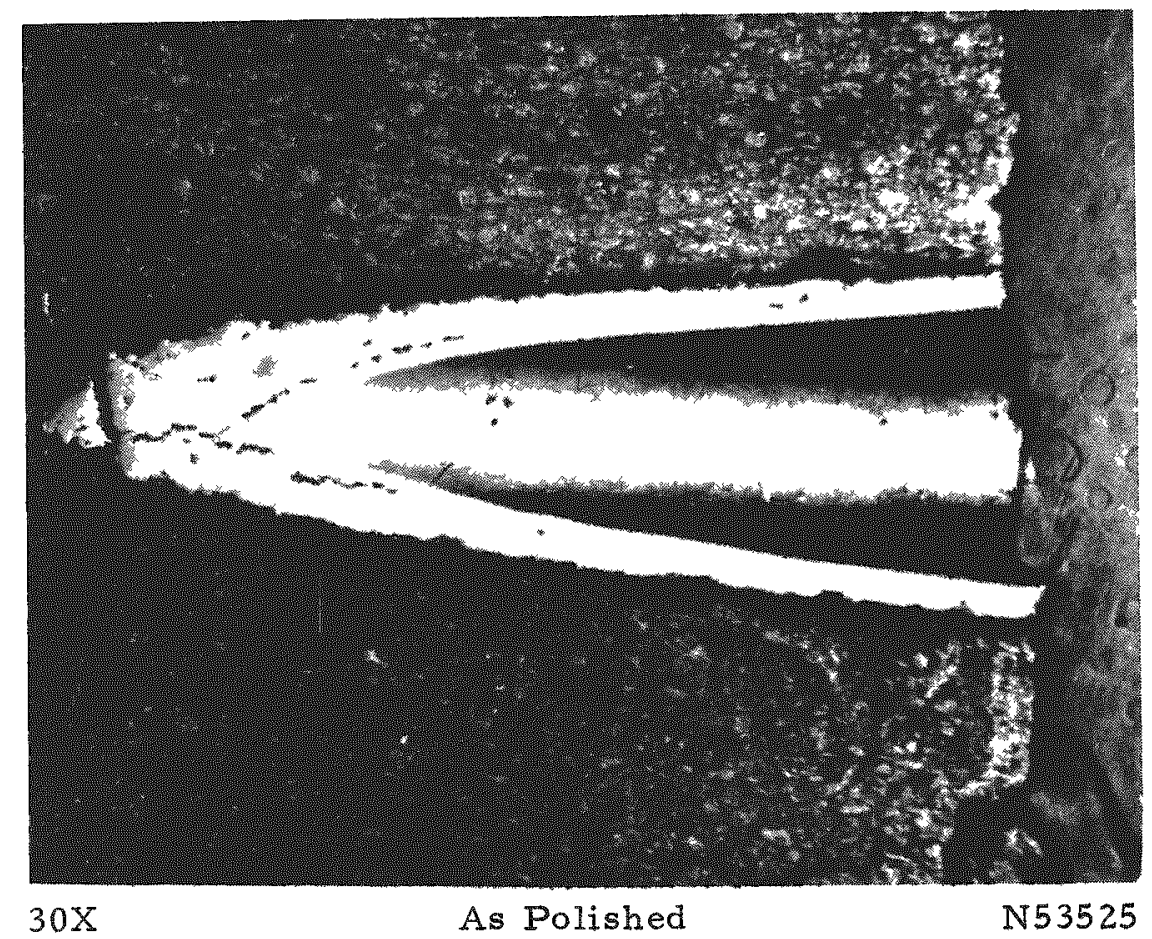

FIGURE 8. NIOBIUM CARBIDE COATING ON TYPE CCU GRAPHITE 
source gave good results for the unloaded specimens. To offset the presence of the uranium in radiographing the loaded specimens, the voltage was raised to $80 \mathrm{kv}$.

Figure 9 is a contact print of the radiograph of a uranium-loaded specimen having a coating of $0.004 \pm 0.001 \mathrm{in}$. in thickness as determined by densitometric comparison with a standard exposed with the specimen. The light area surrounding the tube bore is the region from which the uranium has been leached by the coating vapor with the formation of volatile uranium compounds. The mottled appearance of the bore is significant, having resulted from penetration of the coating into the porous structure of the graphite.

It will be noted that the coating is thin for a short distance at either end of the specimen. This results from the lower temperature at the increased cross section and greater surface area of the adaptors. Since the ends of the specimens were to be similarly cooled by contacts in subsequent tests, no effort was made to improve the temperature distribution and the uniformity of the coating at the ends.

Figure 10 is a $2 X$ reversed radiograph of a coating on the unetched Type CCU dense graphite specimen in the area from which the microsections of Figures 6 and 8 were taken. The smoothness of the bore and the radial cracks are significant. This radiograph should be contrasted with that shown in Figure 11 of an etched and coated specimen. The absence of cracks in the latter is attributed to the anchoring of the coating as indicated by the mottled appearance and the roughened bore.

In order to obtain more accurate values of the coating thickness, it was necessary to radiograph the specimens in a jig provided with lead masks to expose only the tube bore and prevent "undercutting"*. Figure 12 is a contact print of a section of a radiograph of four specimens exposed in this manner. Notches in the lead shields were provided at intervals of about 4-1/4 in. along the specimen for observation of the entire bore and adjacent area. Densitometric measurement shows an apparent decrease in coating thickness within these notches as the result of undercutting.

Shown at the top of Figure 12 are the 4 to 5 -mil and $l$-mil standard coatings on loaded graphite used for calibration of the densitometer. A niobium-foil step-wedge penetrameter was similarly exposed with the unloaded specimens for coating thickness comparison.

\section{Coating Uniformity}

As discussed on page 2 of this report, the possibility existed that the pressure drop through the tube bore might be sufficient to prevent coating formation at the vapor-entrance or high-pressure end. However, in the course of exploratory work, fairly uniform coatings were obtained under some conditions. Thus, it was concluded that this factor would not preclude coating the entire length of the specimen bore.

Since other problems were more pressing, and the coating conditions of $2100 \mathrm{C}$ and 50 $\mathrm{mm}$ of mercury appeared to be satisfactory, no effort was made to define this problem further.

Darkening of the film by lateral reradiation from heavily exposed areas adjacent to the undge of the bore. 


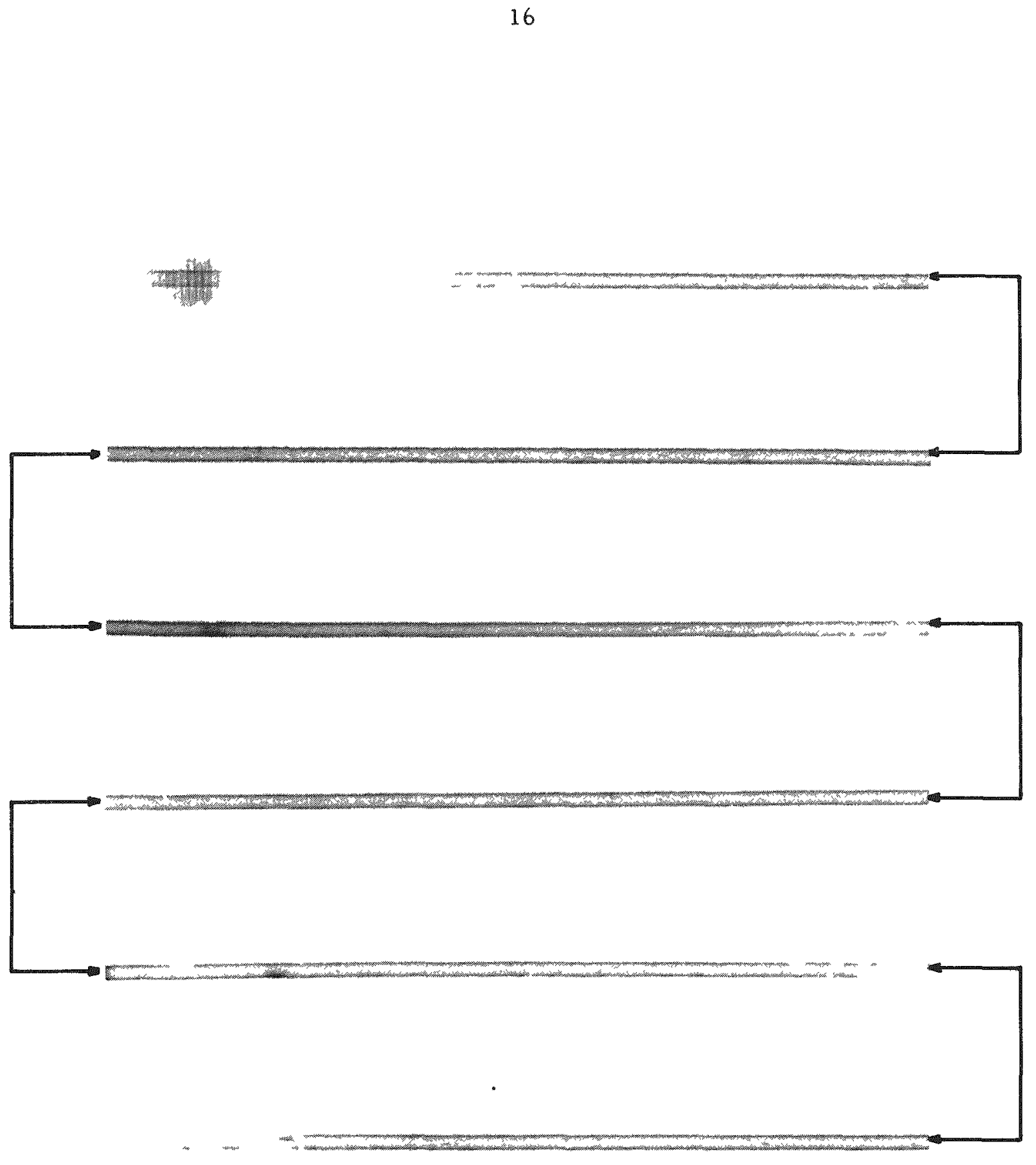

FIGURE 9. RADIOGRAPH OF NbC-COATED URANIUM-LOADED SPECIMEN Contact print. 


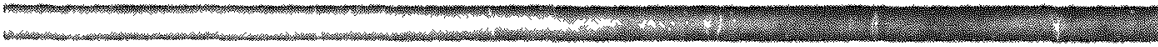

$2 \mathrm{X}$

FIGURE 10. NbC COATING ON UNETCHED DENSE GRAPHITE

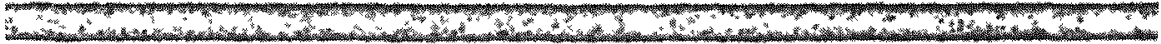

$2 \mathrm{X}$

FIGURE 11. NbC COATING ON ETCHED DENSE GRAPHITE 

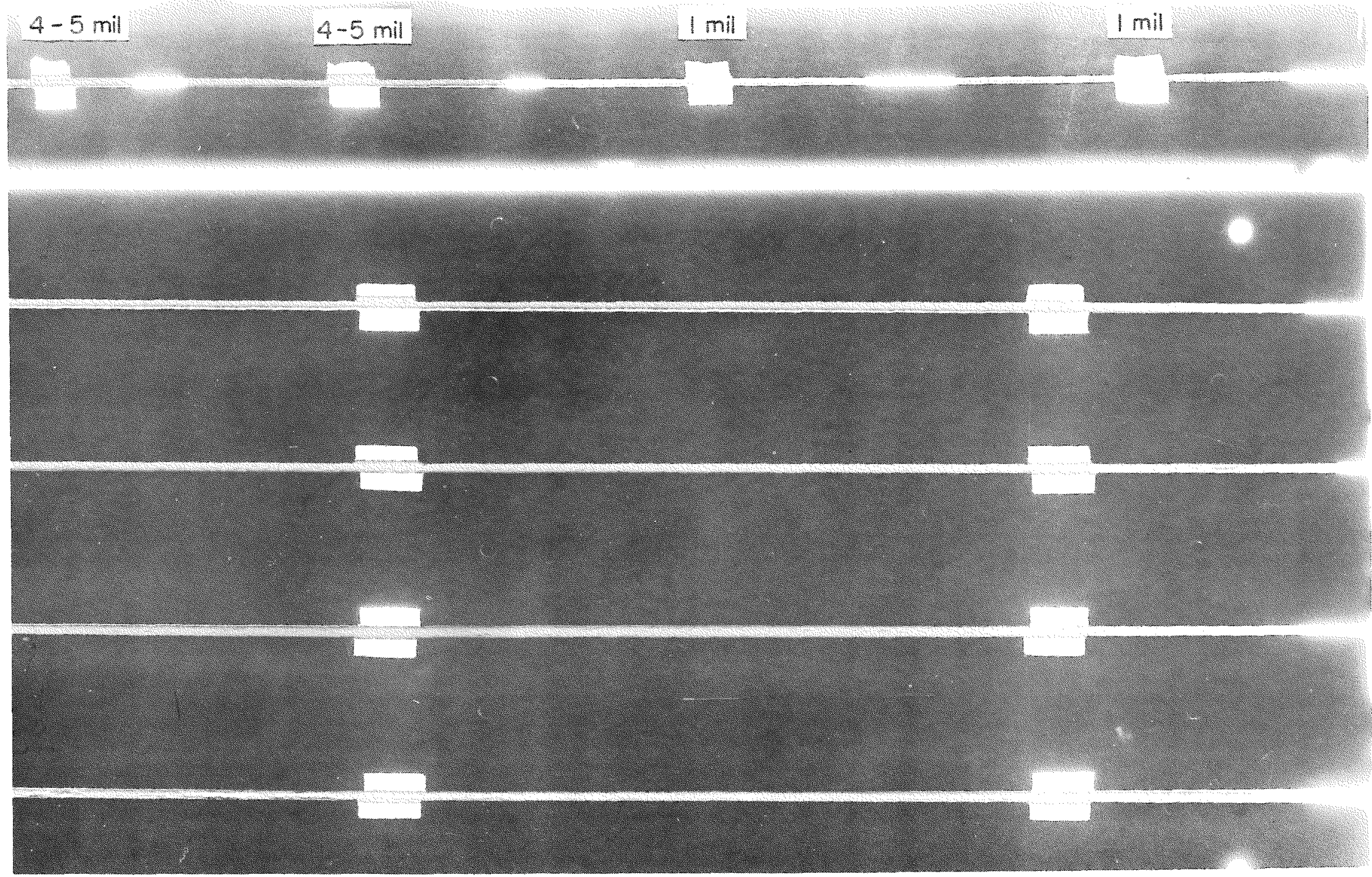

FIGURE 12. NbC-COATED URANIUM-LOADED GRAPHITE TUBES 
Until the $\mathrm{NbCl}_{5}$ vaporizer design shown in Figure 2 had been evolved, thinning out of the coatings at the vapor-exit end of the tube was a problem. The graphite vaporizers first used (without the constriction for operating in the liquid range) were so porous that the major portion of the vapor never reached the tube bore. Leakage at the joints between vaporizer and specimen was eliminated by means of the two types of connections shown in Figure 2, each of which permitted the deformation of the graphite to obtain a seal.

Despite the improvements in the vaporizer-adaptor design, porosity of the adaptor permitted the escape of some vapor which diffused to the specimen and gave an external coating on the lower end. Since this coating interfered somewhat with radiographing of the bore, it was removed mechanically before radiographing except in cases where it was so adherent that its removal could cause destruction of the specimen.

The adherence of this outside coating was quite variable as might be expected from the fact that it was formed from vapor diluted to a variable extent with the inertgas blanket. Such dilution of the vapor defeats the basic principle of the present process, i.e., coating formation controlled by the diffusion of carbon through the carbide. Therefore, the adherence of the external coating could not be considered characteristic of the bore coating which is formed from the undiluted vapor.

Most of the specimens coated routinely were uniform over the bore (except for the ends) to \pm 25 per cent of the average coating thickness. Since this degree of uniformity was held to be adequate for the purpose, further refinement was not justified. It is suspected that such variations in thickness as were observed were primarily the result of temperature gradients in the specimen from end to end\%.

\section{ACKNOW LEDGMENT}

The authors gratefully acknowledge the aid of the following Battelle staff members: W. Hern and R. E. Hagar in specimen coating, V. S. Secrest in chloride preparation and radiograph interpretation, J. H. Oxiley in consultation on fluid flow, C. L. Kimmel in radiograph preparation, J. $R$. Doig in X-ray diffraction analysis, R. D. Buchheit in metallograph preparation, and W. Henry in spectrographic analysis.

\section{REFERENCES}

(1) Blocher, J. M., Jr., Ish, C. J., Leiter, D. P., Jr., Plock, L. F., and Campbell, I. E., "Carbide Coatings on Graphite", BMI-1200 (June 28, 1957).

(2) Blocher, J. M., Jr., and Campbell, I. E., "Carbide Coatings for Graphite", Second Geneva Conference Preprint, A/CONF.15/P/1428.

\footnotetext{
The provision of additional sight ports in the coating apparatus to observe the possible gradient could not be jusified in the present program.
} 
(3) Powell, C. F., Campbell, I. E., and Gonser, B. W., Vapor Plating, John Wiley and Sons, New York (1955).

(4) Reference (1), page 9.

(5) Alexander, K. M., and Fairbrother, F., "The Halides of Niobium and Tantalum. Part I. The Vapor Pressures of Niobium and Tantalum Pentachlorides and Pentabromides", J. Chem. Soc., pp 223-7 (1949).

(6) Schwarzkopf, P., and Kieffer, R., Refractory Hard Metals, The Macmillan Company, New York (1953), p 205.

(7) Brauer, G., Renner, H., and Wernet, J., "The Carbides of Niobium", Z. anorg. allgem. Chem., 277, 249-257 (1954).

(8) Roof, R. B., Jr., and Lombardo, J. J., "A Pseudo-Binary in the U-Nb-C System", Trans. AIME, 212, 50 (1958).

JMB :MF B:DPL:IEC / mmk 